\title{
The Evolution of Business Models within a Business Ecosystem for Cooperative Logistic
}

\author{
Valentina Boschian and Paolo Paganelli \\ Bluegreen Stratetegy srl, \\ Via Sebastiano Serlio 24, 48128 Bologna, Italy \\ \{valentina.boschian, paolo.paganelli\} @bluegreenstrategy.com
}

\begin{abstract}
The aim of this paper consists in presenting a new approach in studying the evolution of the business models of the categories of business actors belonging to a business Ecosystem focused on co-modal logistics networks. Each type of actors is pursuing its own value system on the basis of the key elements that identify and characterize the nature of its activities and business. The focus of the business models is on the key elements that characterize the value-creation links between the involved actors in the Value Chain. The paper focuses on broadening and exploring the traditional concepts of business models showing their evolution when considering the future business environment. To perform this analysis, a template, recalling the wellknown approach by Osterwalder, is proposed, discussed and applied to systematically consider alternative approaches to value creation in terms of reference business models.
\end{abstract}

Keywords: value creation, business models, ecosystem, value chain, logistics networks.

\section{Introduction}

The analysis and the study of issues related to business models is widely addressed in literature, [3], [6], [13], [14], [15], but it is always a very up-to-date topic, since, even if it is extensively investigated in the past and recent years and several definitions are available in literature, the application of business models as a conceptual tool was not as clearly defined in practice as might have been hoped.

In such context, this paper aims at presenting an innovative approach to study the evolution of the business models of the categories of business actors belonging to a business ecosystem focused on co-modal logistics networks. Each type of actors, being part of a business ecosystem as an intentional community of economic actors whose individual business activities share to a large extent the fate of the whole community, [10], [11], [12], is pursuing its own value system on the basis of the key elements that identify and characterize the nature of its activities and business.

The use of the concept of business model increased dramatically during the rise of the so-called 'digital economy' period in the 1990s when companies were actively seeking new ways of doing business. The business model concept offers managers a 
coherent way to consider their options in uncertain and fast-moving environments [9]. A business model of a company can be seen as an essential locus of innovation, and has the potential to disrupt existing industry structures, [1], [19], [8]. Business models can also be used as an analytical tool for the description of business activities of a company, [18]. Business models help in getting everyone in the organization aligned in producing the kind of value the company wants to create. Therefore, the concept has an enormous practical value, [7]. A business model is a holistic concept, which embraces elements such as pricing mechanisms, customer relationships, partnering and revenue sharing [13], [14]. Business models can be seen as focusing on the activity-system side of how a firm creates economic value, [16].

The focus of the business models is on the key elements that characterize the value-creation links between the involved actors in the value chain. Hence, these elements are identified, explored and structured to find out the business model the fit at best the needs of the three main categories of actors. At a conceptual level, a business model includes all aspects of a company's approach to developing a profitable offering and delivering it to its target customers. Research conducted in the last ten years, [17], has established a link between business model innovation and value creation. This research points to the need for organizations to build a competency in business model innovation exploring possible business model alternatives.

Starting from this assumption, the goal of the analysis is to present a new approach that treats business models as a variable and not a constant element. For this purpose, we explore the concept of a business model by addressing the several core questions that the majority of business model researchers deal within their models, but we do not consider that, as it is done usually, [17], the answers to these questions are fixed, and we investigate the new opportunities can be captured by taking into account variable answers to these questions that form the essence of business model evolution.

This work contributes to the project iCargo, [5], Intelligent Cargo in Efficient and Sustainable Global Logistics Operations, sponsored by the European Commission under the $7^{\text {th }}$ Framework Program and aiming at advancing and extending the use of Information and Communication Technology, ICT, to support cooperation between specialized business actors to offer competitive and efficient door-to-door logistic solutions. The paper applies this novel methodology to find out how the iCargo ecosystem modifies the current business scenario and market. In this way we will be able to highlight the impact of iCargo not just as an enabler of operational improvements on the current business, but as a support infrastructure for new value proposition and new ways of cooperation in the logistics market. The iCargo Project is founded on the assumption that interoperable supply chains, including connected intelligent cargo and vehicles, cannot materialize as a result of incremental innovations in individual functional areas or single technology components. Instead, a comprehensive and coordinated stakeholder driven approach is needed, involving multidisciplinary research and development in ICT, co-modal transport networks and strategic management.

The paper is organized as follows: Chapter 2 introduces and defines the core concepts related to the iCargo ecosystem and Reference Value Chain; Chapter 3 describes the proposed approach, Chapter 4 presents the main results obtained by applying the proposed methodology in the iCargo ecosystem and finally Chapter 6 concludes the paper and presents the next steps. 


\section{The iCargo Reference Value Chain}

The iCargo Integrated Project aims at advancing and extending the use of ICT to support new logistics services, [5], that: (i) synchronize vehicle movements and logistics operations across various modes and actors to lower $\mathrm{CO}_{2}$ emissions, (ii) adapt to changing conditions through dynamic planning methods involving intelligent cargo, vehicle and infrastructure systems and (iii) combine services, resources and information from different stakeholders, taking part in an open freight management ecosystem. In the iCargo vision the logistic industry will evolve into a business ecosystem [4], [10], where specialized actors obtain environmental and economic benefits by combining their resources and capabilities.

The iCargo ecosystem is constituted of business communities sharing a common framework, and a semantic enhanced ICT infrastructure supporting interoperability and cooperation between software services, company systems and intelligent objects. The iCargo ecosystem encompasses existing business communities, allowing them to keep their standards at the same time enlarging the scope of their interactions. These aspects trigger modifications in the current business scenarios by introducing new and value-added elements that heavily influence the business models of the involved companies.

The categories of companies that will be considered are the Logistic Service Client (LSC) as the user purchasing the door-to-door service solution, the Freight Service Integrator (FSI) as the user providing the combined door-to-door service to the LSC, the Logistic Service Provider (LSP) as the user providing transport and logistic services contributing to the door-to-door solution like, and the Information Services Integrator (ISI) as the organization providing the information infrastructure of the iCargo ecosystem. The other two roles in the iCargo Value Chain are only marginally addressed, as they are not directly involved as services providers, and this are not expected to develop Business Models for iCargo. These are the Transportation Network Manager (TNM) as the organization in charge of managing of the transportation infrastructure sustaining the door-to-door flow like, the Transport Regulator (TR) as the organization receiving all mandatory reporting and checking if reporting has been carried out, in order to ensure that all services are completed according to existing rules and regulations.
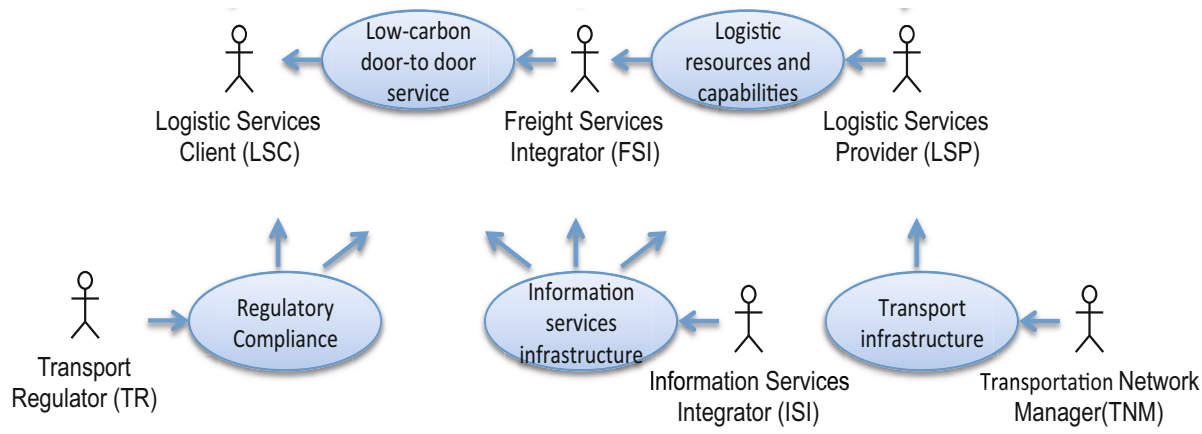

Fig. 1. iCargo Reference Value Chain 


\section{The Proposed Methodology}

We propose the following innovative methodology to find out the evolution of the market due to the iCargo innovations:

1. Collection of data about the current business models in the market, on the basis of the Osterwalder Canvas, implemented by the companies belonging to the LSC, FSI, LSP, and ISI categories. The canvas is derived from the business model ontology by Osterwalder, [13], [14], in which nine building blocks are the core of the business model are proposed. These building blocks are customer segments, value proposition, channels, customer relationships, revenue streams, key resources, key activities, key partnerships, and cost structure.

2. Mapping the current implemented business models by the different involved actors and the business and technical innovations introduced by iCargo to show the advantages conveyed by the iCargo new low carbon door-to-door services in the current business scenarios. In the proposed approach, we link the iCargo business and technical innovations to the dimensions of the Canvas to find out the effect of these benefits on the business models and, in particular, how the elements that characterize the business models of each category of actors are influenced by these new solutions.

3. Creating a template that allows to examine the new business models to systematically consider alternative approaches to value creation in terms of reference business models. The questions that help to shape a business model represent a series of decisions, each of which has a set of possible outcomes: (i) no change on current dimension of the business model, either because it is outside the company's business or because the company already provides a suitable solution; (ii) change in terms of not a new solution but an adaptation of the current model, for the company to stay competitive in the iCargo ecosystem. The change is not so relevant as to require a significantly different business model, but some aspects still need to be changed; (iii) disruption in terms of a solution that does not fit the company's current model. Moreover, the iCargo solution will be implemented in an entirely different way that, if successful, will put the company current solution out of the market as obsolete or no longer needed; (iv) opportunity in terms of a new solution, not fitting the company's current offer, but the company is in the position to provide it by evolving its business model. Hence, the company has the strategic opportunity to provide the new solution by leveraging its current assets and expertise. The "opportunity" case indicates a challenge, too, since if the opportunity is missed it may actually become a disruption, [2].

Selecting one possibility from each category and then linking them together forms one potential new way to proceed. And, of course, selecting different combinations creates other possible outcomes. Fig. 2 below depicts an extract from an example of possible evolution of the current business model into different new business models, indicated as BM.

4. Definition of the iCargo ecosystem and description of the evolution of the current market to the future iCargo ecosystem, see Chapter 4. 


\section{Elements of the Osterwalder Canvas}

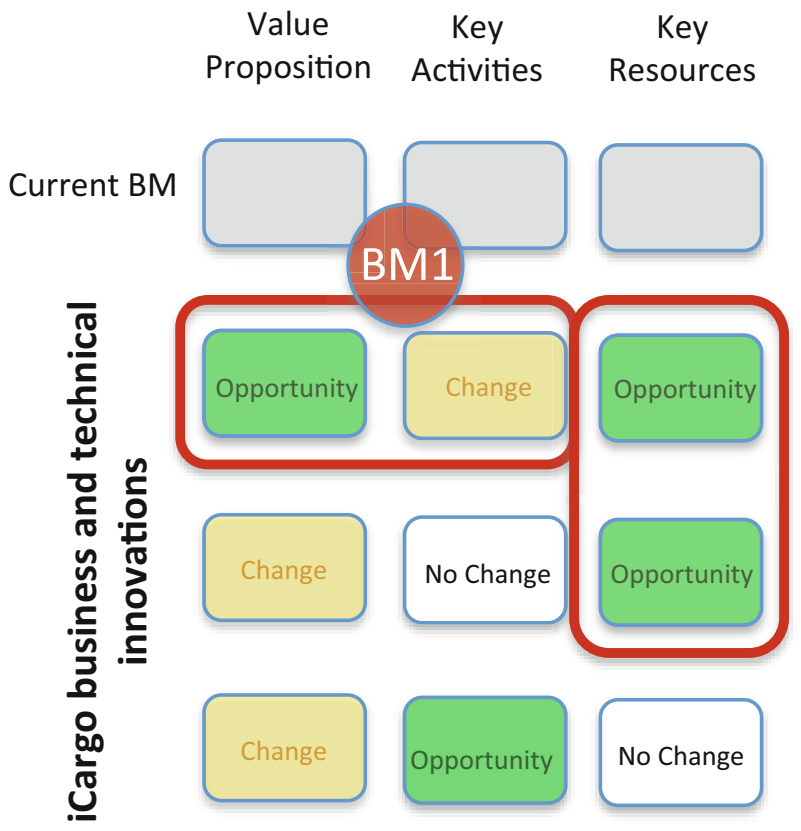

Fig. 2. Proposed approach to analyse the evolution of the business models

\section{The Main Results}

From the general theory of business ecosystems, [4], [10], [11], [12], there are two foundational components in a business ecosystem: (i) first, it is a necessary to create value within the ecosystem in order to attract and retain clients and providers, thus providing growth potential for the ecosystem. In the case of iCargo, this means delivering better, less expensive and less pollutant logistic services, based on the foreseen business and technical innovations; (ii) second, an appropriate ecosystem structure is needed to share the value within the ecosystem. The different species of business actors must find their own well-defined and relatively secure value propositions, relying on other actors for complementary products and services.

The complete iCargo Business Ecosystem in its mature stage is represented in Fig. 3 below: there are the six roles in the iCargo Reference Value Chain, represented by rounded rectangles. For each role, the corresponding reference Business Model is identified, represented by circles of different colors showing the different types of evolution in the iCargo ecosystem: (i) blue: pre-existing models that may grow or shrink in the iCargo ecosystem, (ii) green: new models, made possible by iCargo, (iii) red: models that will be disrupted because of iCargo. Solid arrows represent provision of products or services from one role to the other, whereas dashed arrows represent evolution from one Business Model (one circle) to the other. 


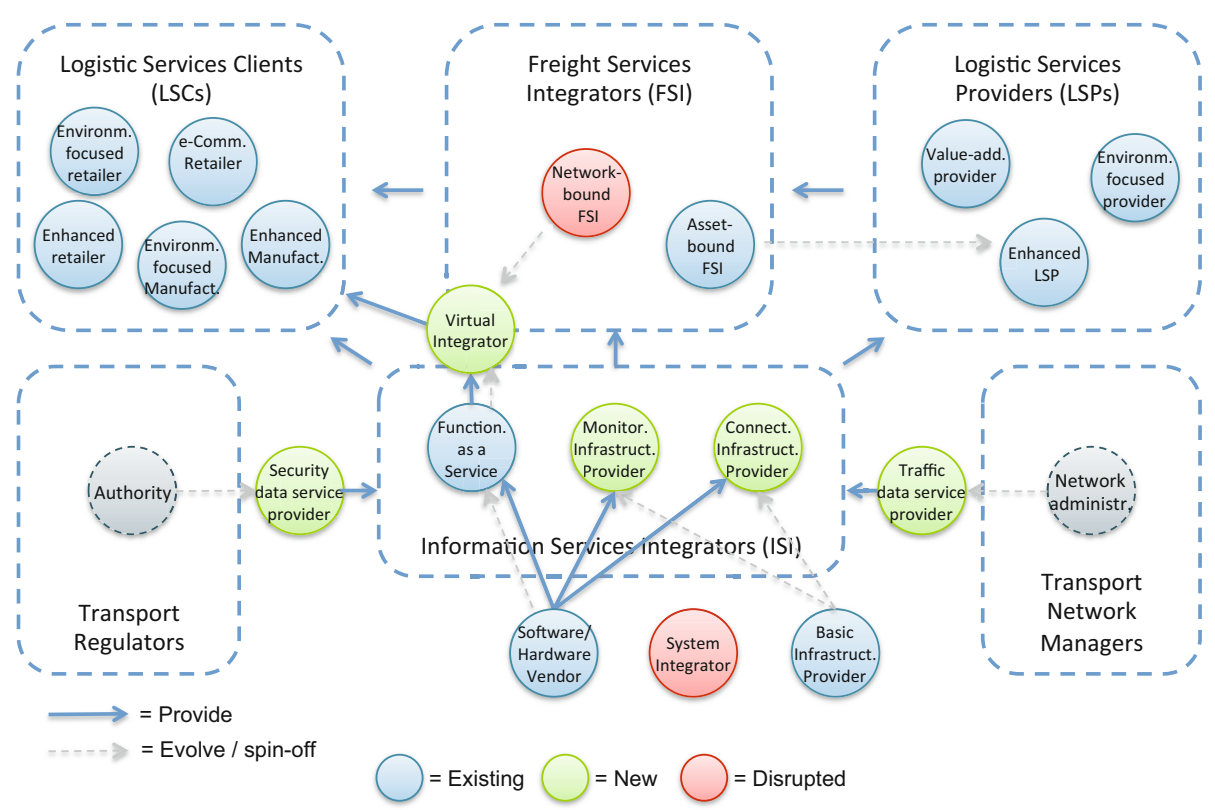

Fig. 3. iCargo Business Ecosystem evolution

The overall iCargo ecosystem picture results from the following considerations. The Logistic Service Client role will see no disruption of current business models, all companies will have the opportunity to enhance their business through iCargo, by becoming environment-focused retailers and manufacturers, and/or e-commerce based retailers. Logistic Services Providers will have a similar evolution, being pushed by their clients and by the iCargo opportunity to evolve towards environmentfocused business models. Traditional asset-bound integrators, such as warehousing companies or terminal operators, will re-focus their value proposition on their core services rather than on the integration, thus going back to the LSP role. The business model of network-bound integrators, such as supply-chain outsourcers or closed marketplaces, will be disrupted. Instead, Virtual Integrators will emerge as providers of pure information services and competencies for better composing, planning and monitoring logistic chains in iCargo. The traditional system integrator model, developing ad-hoc platforms and services for interoperability, will disappear. Interoperability on the business level will be provided as a service from Connectivity Infrastructure Providers. These will likely evolve into Monitoring Infrastructure Providers, offering logistics monitoring as a combination of hardware/infrastructure rental and services. Software and hardware vendors will remain as providers of specialized functionality to the other information services providers in iCargo. Transport Regulators, like custom authorities, and Transport Network Managers, like road administrators are expected to make available relevant information that they handle acquiring distribution rights for these types of information services. 


\section{Conclusions}

The main results of the presented work deal with the study of the evolution of the business models of the main category of actors involved in the iCargo Reference Value Chain. The impact of iCargo in the current business models has been detailed and specified in relation to the influence of its business and technical innovations on the nine dimensions of the Osterwalder business model Canvas.

These results are particularly important in the iCargo project and represent a common basis for the exploitation planning phase. The next steps will focus on the validation of the results with the iCargo involved actors in order to increase the understanding of using business models in the development of possible future business options.

The innovation of the proposed approach is related to the exploration of the business model concept as an evolution and not only as a static analysis in order to capture systematically new opportunities that are not currently addressed.

By analyzing the value creation and business logic of companies by using the business model framework, it is possible to develop a solid understanding about the principles and dynamics of a specific industry. The business model also highlights the critical service related issues like relationships with customers needing special attention in the industry's development, and it can be utilized in designing new services, too. The proposed approach could be also generalized to other applications and domains in which the key issues concern the investigation of the value creations and the effect of innovative strategies on the current business models.

Acknowledgments. The paper presents the work carried on within the Intelligent Cargo in Efficient and Sustainable Global Logistics Operations, iCargo, project.

\section{References}

1. Amit, R., Zott, C.: Value Creation in e-Business. Strategic Management Journal 22, 493-520 (2001)

2. Anthony, S.D., Johnson, M.W., Sinfield, J.V., Altman, E.J.: Innovator's Guide to Growth Putting Disruptive Innovation to Work. Harvard Business School Press (2008)

3. Göthlich, S., Hagen, E., Wenzek, R.: Underlying Principles of Business Ecosystems. Institute for Business Value (2004)

4. Iansiti, M., Levien, R.: Strategy as ecology. Harvard Business Review, pp. 1-12 (March 2004)

5. iCargo Consortium, iCargo Deliverable D1.3 - iCargo Vision (2012)

6. Johnson, M.W., Christensen, C.M., Kagermann, H.: Reinventing Your Business Model. Harvard Business Review 86(12), 51-59 (2008)

7. Magretta, J.: Why Business Models Matter. Harvard Business Review 80, 86-92 (2002)

8. Markides, C., Charitou, C.D.: Competing With Dual Business Models: A Contingency Approach. Academy of Management Executive 18, 22-36 (2004)

9. McGrath, R.G.: Business Models: A Discovery Driven Approach. Long Range Planning 43, 247-261 (2010)

10. Moore, J.F.: Predators and prey: a new ecology of competition. Harvard Business Review, pp. 75-86 (1993) 
11. Moore, J.F.: The Death of Competition: Leadership \& Strategy in the Age of Business Ecosystems. Harper Business, New York (1996)

12. Moore, J.F.: Business ecosystems and the view from the firm. Antitrust Bull. 51(1), 31-75 (2006)

13. Osterwalder, A.: The Business Model Ontology. A Proposition in a Design Science Approach. University of Lausanne, Dissertation (2004), http: / / www. hec.unil.ch/aosterwa/PhD/

14. Osterwalder, A., Pigneur, Y., Tucci, C.L.: Clarifying Business Models: Origins, Present, and Future of the Concept. Communications of the Association for Information Systems 15, 1-25 (2005)

15. Shafer, S.M., Smith, H.J., Linder, J.C.: The power of business models. Business Horizons 48(3), 199-207 (2005)

16. Business Horizons, 48(3). Elsevier (2005)

17. Seddon, P.B., Lewis, G.P., Freeman, P., Shanks, G.: The Case for Viewing Business Models as Abstractions of Strategy. Communications of the Association for Information Systems 13, 427-442 (2004)

18. Sinfield, J.V., Calder, E., McConnell, B., Colson, S.: How to identify New Business Models. Management Review. Emerald Group Publishing Limited 28(10), 18-22 (2011)

19. Teece, D.: Business Models, Business Strategy and Innovation. Long Range Planning 43, 172-194 (2010)

20. Zott, C., Amit, R.: The Fit Between Product Market Strategy and Business Models: Implications for Firm Performance. Strategic Management Journal 29, 1-6 (2008) 